\title{
Jackfruit Seed Extract Exposure on Zebrafish Embryos as Initial Screening Model for Covid-19 Treatment
}

\author{
Atika Ayu Kusumaningtyas ${ }^{1,2}$ Bambang Retnoaji ${ }^{1, *}$ \\ ${ }^{1}$ Dept. of Biology, Universitas Gadjah Mada, Indonesia \\ ${ }^{2}$ Magister Program in Biology, Dept. of Biology, Universitas Gadjah Mada, Indonesia \\ *Corresponding author. Email: bambang.retnoaji@ugm.ac.id
}

\begin{abstract}
The World Health Organization establishes the coronavirus COVID-19 as a pandemic in March 2020. The receptor-binding protein in Coronavirus will bind to ACE-2 found in the heart, lungs, kidneys, and digestive tract, facilitating the entry of the virus into cells target to infect its host. High infection rates and an undiscovered COVID-19 vaccine encourage disease prevention. Several alternatives used for herbal plants have been recommended, one of which is jackfruit seed (Artocarpus heterophyllus). This study aims to screen the use of jackfruit seed extract (JSE) on the development of zebrafish embryos. This study used an experimental method with a randomized block design (RBD) and each treatment was repeated 3 times. The zebrafish were grouped into three treatment and one control groups. The concentration of jackfruit seed extract (Artocarpus heterophyllus) was $10,7.5,5$, and $0 \mathrm{ug} / \mathrm{mL}$ for the control group, respectively. Result showed no effect of JSE on the morphological features, hatching and survival rate as well as heartbeat rate in all treatments. All embryos showed normal development as indicated by the detachment of tail - yolk sac and midbrain-hindbrain boundaries formation at $24 \mathrm{hpf}$. The heartbeat rate showed no differences between JSE treatment and control; both showed a standard heart rate between $140-180 \mathrm{bpm}$. Moreover, Statistical analysis conducted on the data showed no significant differences on each treatmen. In conclusion, the JSE treatment didnot caused development defect on zebrafish embryos.
\end{abstract}

Keywords: ACE-2, Artocarpus heterophyllus, Zebrafish, COVID-19

\section{INTRODUCTION}

The World Health Organization establishes the coronavirus COVID-19 as a pandemic in March 2020. This outbreak was first discovered in the city of Wuhan, Hubei province, China and has spread to 6 continents and more than 157 countries, including Indonesia [1-3]. This disease is caused by the pathogen severe acute respiratory syndrome coronavirus 2 (SARS-CoV-2) and transmitted through droplets, with an incubation period ranging from 2 to 14 days after exposure to the virus.

SARS-CoV-2 has genetic material in the form of positive-sense RNA wrapped in an envelope with protein spikes scattered on the outside to resemble a crown. $S$ protein in the SARS-CoV-2 envelope functions as a receptor-binding domain or RBD [4,5]
RBD will bind to angiotensin-converting enzyme 2 or ACE-2, facilitating the virus's entry into target cells $[6,7,4]$. ACE-2 is found in the heart, lungs, kidneys, and digestive tract.

Efforts that can be made to prevent this disease are to increase the immune system and control ACE2 activation. Flavonoids are compounds that have immunomodulatory effects. Flavonoids and their derivatives are able to inhibit various transcriptional factors so that they can modulate the differentiation, proliferation, and activation of immune cells and increase regulation of $\mathrm{T}$ cell formation [8].

Hosseinzade et al. [9] research showed flavonoids could suppress the mTOR pathway, which functions as a mediator in metabolism and the immune system and also can induce $\mathrm{T}$ regulatory subsets to form $\mathrm{Th}$ cells that play a role in the immune system. The study 
of flavonoids from citrus or its derived phytochemicals shows the potential of anticoronavirus and anti-inflammatory activity of flavonoids, which can be used to prevent and treat 2019-nCoV infection [10].

One of the plants that contain flavonoids is jackfruit seeds. Jackfruit (Artocarpus heterophyllus) seeds were chosen as a manifestation of optimal utilization among the community. Shanmugapriya et al. [11] research showed that $100 \mathrm{mg}$ ethanolic fraction of jackfruit seed extract contained higher flavonoids than the fraction of acetone, ethyl acetate and water, namely $4.05 \pm 0.01 \mathrm{mg} / \mathrm{g}$. Jackfruit seeds also contain secondary metabolite compounds called jacalin, which have an anti-inflammatory function, and also anti-angiogenic activity $[12,13]$.

This study used Zebrafish embryos as a model organism. Zebrafish have an immune system that has been shown to be similar to humans [14]. Besides, these fish also develop $\mathrm{T}$ cells and thymus that are very similar to mammals [15]. Chou et al., [16] added that Zebrafish has the same ACE-2 identity as humans by $65 \%$. Hoffmann et al., [17] added that Zebrafish also have genes similar to humans, namely At1, At2, and the renin, angiotensinogen, ACE, and ACE-2 receptors which make Zebrafish ideal as a model organism related to this study. This study aims as the initial stage of screening the use of jackfruit seed extract on the development of zebrafish embryos.

\section{MATERIALS AND METHODS}

\subsection{Preparation of Zebrafish Embryos}

Wild type Zebrafish (Danio rerio) were obtained from Leiden University and cultivated at the Faculty of Biology, UGM. Zebrafish embryos were collected from matured wild type $\mathrm{AB} / \mathrm{TL}$ that have been spawned and inspected under a microscope to ensure that only fertilized embryos were used in this study.

\subsection{Plant Extracts}

A whole jackfruit (Artocarpus heterophyllus) was purchased from local farmers in Semin, Gunung Kidul, Yogyakarta. The seeds were used in this study. The fresh seeds were processed into powder by thinly cutting the seeds and then sun-dried for a few days to reduce moisture content then ground into fine powder. The crude extract of jackfruit seeds was prepared using the maceration method by soaking 25 $\mathrm{g}$ seed powder into $500 \mathrm{~mL}$ Etanol $70 \%$ and then processed into crude extract using rotary flash evaporator (Coleparmer Stuart RE 300) for $4 \mathrm{hrs}$. The acquired extract then stored in refrigerator for further uses.

\subsection{Treatment, Evaluation of Zebrafish Embryos and Data Analysis}

Toxicity test was carried out by distributing one fertilized embryos using a transfer pipette in each well [19]. Then embryos were submerged in egg water (contain salt stock and methylene blue as antifungal agent) containing three concentrations of jackfruit seed crude extract from 10, 7.5, and 5 $\mathrm{ug} / \mathrm{mL}$ [20] and one control. Five embryos were used for each concertation with three repetitions, so a total of 60 embryos, including control, were used in this study.

Plates were inspected at 24, 48, 72, 96 hpf using a compound microscope (Boeco). Survival rate was determined by the number of embryos surviving at each hour compared to the total number of embryos. The hatching rate was determined by the number of embryos that hatched at 48, 36, 72, and $96 \mathrm{hpf}$ compared with the total number of embryos. Four apical observations are recorded as indicators of lethality based on OECD [19]. Formation of the otic placode, midbrain-hindbrain boundaries, and pigmentation was observed as an indication of normal development.

The Data were analyzed quantitatively using assessment of egg hatching, embryo survival and heart rate and qualitatively using a morphological feature of the developing embryos. The determined treatment effect on embryos was tested by One-way ANOVA and Duncan test with the SPSS 21 application.

\section{RESULTS AND DISCUSSION}

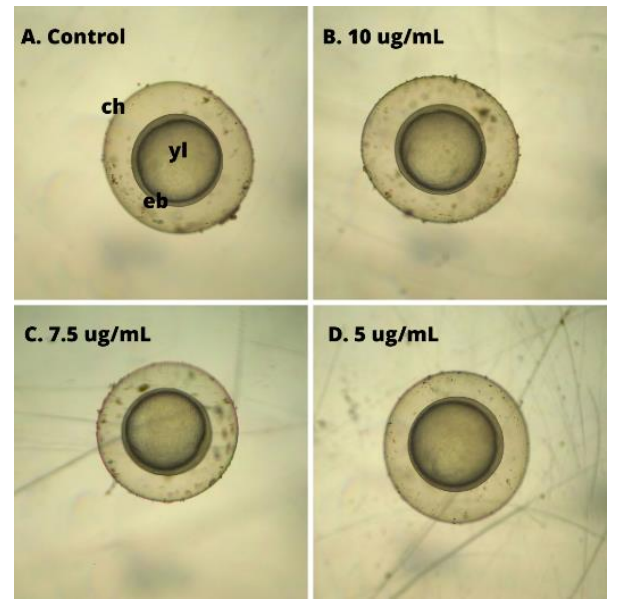

Figure 1. Zebrafish embryos on the Epibolic stage were treated with different concertation of JSE. yl: yolk; eb: embryo; and ch: chorion. 

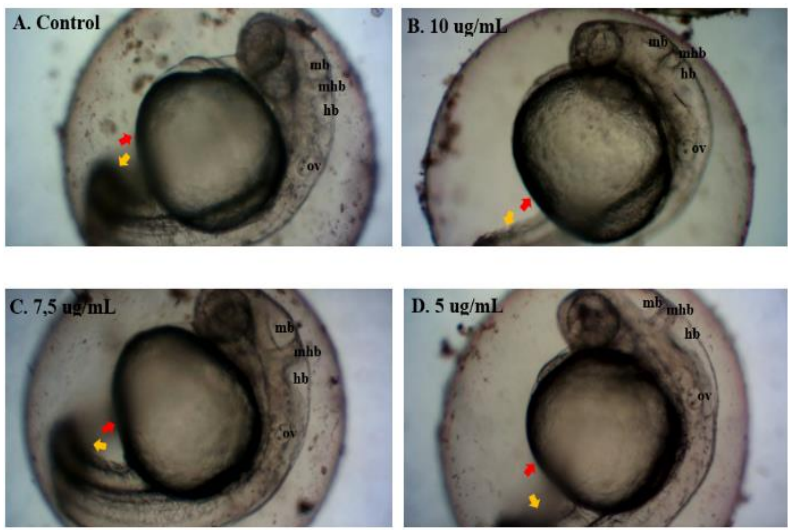

Figure 2. 24 hours post-fertilization (hpf) Zebrafish Embryos showed structural similarity between control and JSE treatment. Both embryos indicate normal development by the detachment of tail-bud (yellow arrow) from yolk sac (red arrow). mb: midbrain; mhb: midbrain-hindbrain boundaries; hb: hindbrain; and ov:otic vesicle/placode.

Zebrafish embryos were exposed to jackfruit seed extract at the epibolic developmental stage as seen in Fig 1. The epibolic stage is crucial in embryo development, which occurs before gastrulation. This stage determines the cell movement during gastrulation [21]. Exposure to toxic substances at this stage can lead to malformation in embryos and larvae [22]. Observation on early embryo development (24 hpf) showed no effect of Jackfruit Seed Extract (JSE) and showed no coagulation of fertilized eggs.

As shown in Fig 2. the morphological features showed no lack of somite formation by both embryos (control and JSE treatment) characterized by the detachment of tail-bud from the yolk sac, formation of otic placode, segmentation between midbrain and hindbrain, an early heartbeat that occur in $24 \mathrm{hpf}$ observation.

The stage between 10-24 hpf called the segmentation period [21]. In this period, somites are developed undifferentiated mesodermal components of the early trunk and tail segmented [23], followed by tail well extended, spontaneous movement, early pigmentation, and heart beating.

The midbrain-hindbrain boundaries (MHB) also known as isthmic coordinator situated at the intersection of midbrain and hindbrain neuromeres $[24,25]$. Important characteristic of developing brain morphologically indicated by the presence of the MHB which are critical for its function such as signaling center, a guide for neuronal migration, and axon pathfinding [26] also as a physical separation of brain ventricles [8]. A developing MHB indicates the normal development of the embryos. This shows that JSE treatment did not affect Zebrafish embryos.
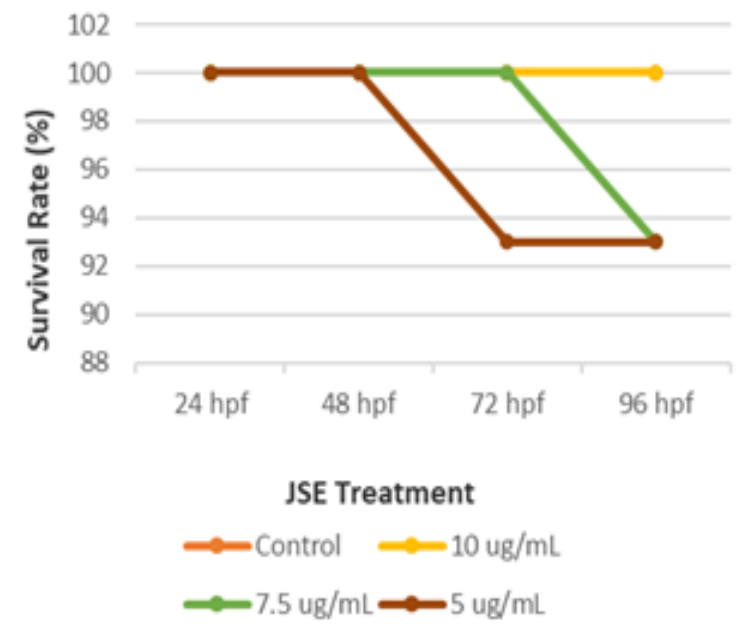

Figure 3. 24 hours post-fertilization (hpf) Zebrafish Embryos showed structural similarity between control and JSE treatment. Both embryos indicate normal development by the detachment of tail-bud (yellow arrow) from yolk sac (red arrow). mb: midbrain; mhb: midbrain-hindbrain boundaries; hb: hindbrain; and ov:otic vesicle/placode.

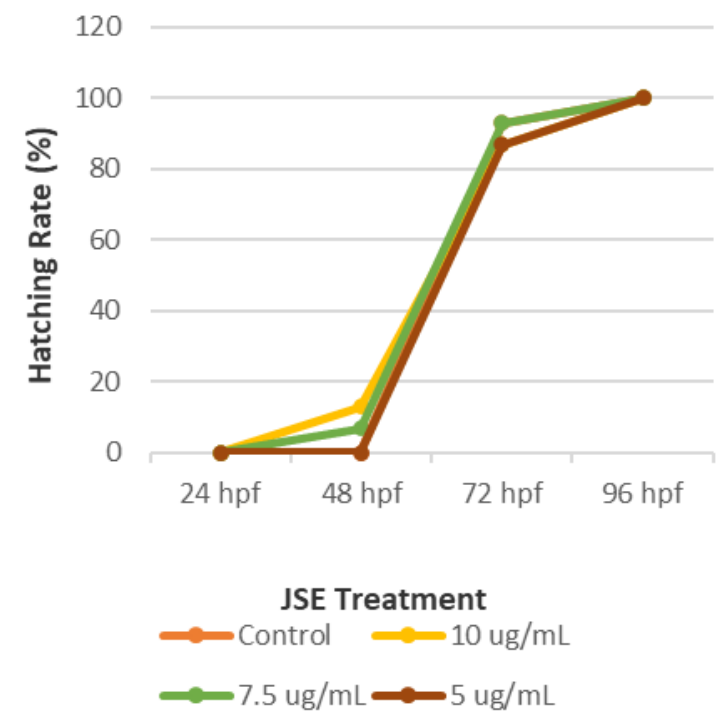

Figure 4. Hatching rate of zebrafish embryo in the control group and different JSE treatment concentrations at different hours postfertilization (hpf). All measurements were made in triplicate. Anova analysis (*P <0.05) showed there is no significant change in control and treated embryos at all hours postfertilization ( $h p f)$.

The survival of zebrafish embryos exposed to different concertation of JSE was determined at specific time points. As shown in Fig 3. Almost all concertation exhibited no toxicity to Zebrafish embryos. Moreover, survival of the embryos was more than $90 \%$ for the entire period of observation. 
Compared with controls, the survival rate did not differ significantly $(p<0.05)$ on JSE treatment. JSE treatment did not affect the decreasing survival rate of the zebrafish embryo.

The hatching rate of zebrafish embryos exposed to different concertation of JSE at various stages is shown in Fig 4. Compared with the control group, all JSE treatments did not significantly affect the hatching rate between $48 \mathrm{hpf}, 72 \mathrm{hpf}$, and $96 \mathrm{hpf}$ (p $<0.05$ ). Generally, zebrafish embryo hatch at age 48 $h p f$ and $72 h p f[21]$.

The result shows a delay in some embryos. Hatching delays occurred both in control and JSE treatment groups. Despite the delay in hatching, statistical analysis showed that there was no difference between the control and JSE treatment group.

Zebrafish embryos naturally developed at $26 \pm 1^{\circ}$ $\mathrm{C}$ and the heart rate can be measured after $48 \mathrm{hpf}$ [19]. The effect of JSE treatment on Zebrafish embryos was observed at $48 \mathrm{hpf}, 72 \mathrm{hpf}$, and $96 \mathrm{hpf}$ can ben seen in Fig 5 .

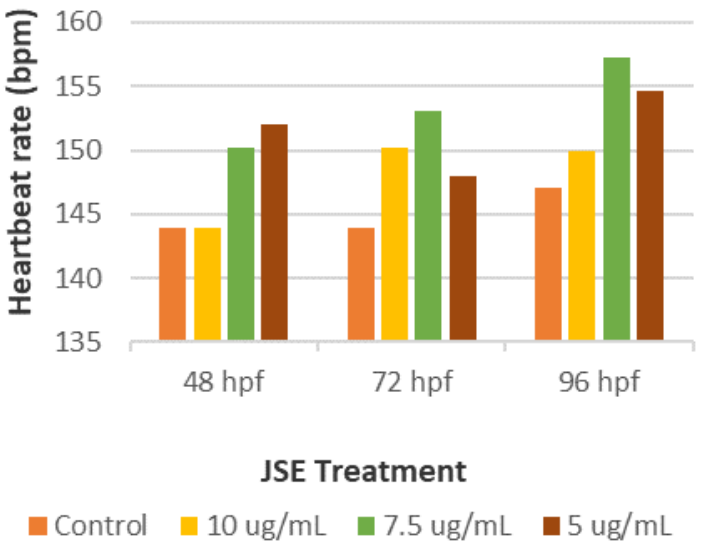

Figure 5 Heartbeat rate performance of the embryos. Anova analysis $(\mathrm{P}<0.05)$ showed no significant change in control and treated embryos at all hours postfertilization ( $h p f)$.

Embryos at $48 \mathrm{hpf}$ showed heart rate in control treatment $144 \mathrm{bpm}, 10 \mathrm{ug} / \mathrm{mL} 144 \mathrm{bpm}, 7.5 \mathrm{ug} / \mathrm{mL}$ $150 \mathrm{bpm}$, and $5 \mathrm{ug} / \mathrm{mL} 152 \mathrm{bpm}$. While the $72 \mathrm{hpf}$ embryos showed heart rate in control 144 beats / minute, $10 \mathrm{ug} / \mathrm{mL} 150$ beats / minute, $7.5 \mathrm{ug} / \mathrm{mL}$ 153 beats / minute, and $5 \mathrm{ug} / \mathrm{mL} 148$ beats / minute and the 96 embryos showed heart rate in control 147 beats / minute, $10 \mathrm{ug} / \mathrm{mL} 150$ beats / minute, $7.5 \mathrm{ug}$ / $\mathrm{mL} 157$ beats / minute, and $5 \mathrm{ug} / \mathrm{mL} 155$ beats.

Generally, a regular Zebrafish heart rate is around 120-180 bpm [27] meanwhile OECD [19] stated that naturally developed embryos heart rate of at least 80 bpm. This indicates that both control and JSE treatment did not affect the heartbeat rate performance.

JSE exposure in early zebrafish embryo development showed no effect on decreasing survival, hatching, and zebrafish embryos' heart rate. Statistical analysis showed that there was no difference between the JSE treatment group and the control group. Meanwhile, morphological observations show that there is no malformation in the embryonic yolk. In embryos aged $24 \mathrm{hpf}$ there has also been a tail - yolk sac detachment and midbrainhindbrain boundaries, which is an indicator of normal embryo development. This study provides an overview of the use of Zebrafish as a screening model for testing the JSE.

\section{CONCLUSION}

Jackfruit Seed Extract has no significant effect on morphology, survival rate, hatching rate, and zebrafish embryos' heart rate. The Zebrafish has been developed in this study as a reliable in vivo screening model for JSE treatment. This suggests that both JSE and Zebrafish are good candidates for COVID-19 treatment and further experiments.

\section{ACKNOWLEDGMENTS}

The authors acknowledge all people involved in this research, Universitas Gadjah Mada and financial support provided by KEMENRISTEKDIKTI through Penelitian Tesis Magister 2020. Letter Task No. 6/AMD/E1/KP.PTNBH/2020 and 3007/UN1.DITLIT/DIT-LIT/PT/2020.

\section{REFERENCES}

[1] F.A. Rabi, M.S. Al Zoubi, A.D. Al-Nasser, G.A. Kasasbeh, D.M. Salameh, Sars-cov-2 and coronavirus disease 2019: What we know so far, Pathogens 9(3) 1-14 (2020). DOI: https://doi.org/10.3390/pathogens9030231

[2] L. Wang, Y. Wang, D. Ye, Q. Liu, A review of the 2019 Novel Coronavirus (COVID-19) based on current evidence, International Journal of Antimicrobial Agents (2020). DOI: https://doi.org/10.1016/j.ijantimicag.2020.10594 $\underline{8}$

[3] D. Wu, T. Wu, Q. Liu, Z. Yang, The SARSCoV-2 outbreak: what we know, International Journal of Infectious Diseases (2020). DOI: https://doi.org/10.1016/j.ijid.2020.03.004 
[4] W. Tai, L. He, X. Zhang, J. Pu, D. Voronin, S. Jiang, L. Du, Characterization of the receptorbinding domain (RBD) of 2019 novel Coronavirus: implication for development of RBD protein as a viral attachment inhibitor and vaccine, Cellular \& Molecular Immunology (2020). DOI: https://doi.org/10.1038/s41423020-0400-4

[5] G.K. Thomas, D. Erdman, S.G. Cynthia, R.Z. Sherif, T. Peret, S. Emery, C. Humprey, A Novel Coronavirus Associated with Severe Acute Respiratory Syndrome, The New England Journal of Medicine 348(20) 1953-1966 (2003). DOI: $\underline{\text { https://doi.org/10.1056/NEJMoa0900212 }}$

[6] M. Hoffmann, H. Kleine-Weber, S. Schroeder, N. Krüger, T. Herrler, S. Erichsen, S. Pöhlmann, SARS-CoV-2 Cell Entry Depends on ACE2 and TMPRSS2 and Is Blocked by a Clinically Proven Protease Inhibitor, Cell 1-10 (2020). DOI: https://doi.org/10.1016/j.cell.2020.02.052

[7] X. Ou, Y. Liu, X. Lei, P. Li, D. Mi, L. Ren, Z. Qian, Characterization of spike glycoprotein of SARS-CoV-2 on virus entry and its immune cross-reactivity with SARS-CoV, Nature Communications 11(1) (2020) DOI: https://doi.org/10.1038/s41467-020-15562-9

[8] L.A. Lowery, G. De Rienzo, J.H. Gutzman, H. Sive, Characterization and classification of zebrafish brain morphology mutants, Anatomical Record (2009). DOI: https://doi.org/10.1002/ar.20768

[9] A. Hosseinzade, O. Sadeghi, A.N. Biregani, S. Soukhtehzari, G.S. Brandt, A. Esmaillzadeh, Immunomodulatory effects of flavonoids: Possible induction of T CD4+ regulatory cells through suppression of mTOR pathway signaling activity, Frontiers in Immunology 10(01) 1-12 (2019). DOI: https://doi.org/10.3389/fimmu.2019.00051

[10] L. Cheng, W. Zheng, M. Li, J. Huang, S. Bao, Citrus fruits are rich in flavonoids for immunoregulation and potential targeting ACE2, Preprints (2020).

[11] K. Shanmugapriya, P.S. Saravana, H. Payal, S. Peer Mohammed, W. Binnie, Antioxidant activity, total phenolic and flavonoid contents of Artocarpus heterophyllus and Manilkara zapota seeds and its reduction potential, International Journal of Pharmacy and Pharmaceutical Sciences 3(5) 256-260 (2011).

[12] S. Kabir, Jacalin: A jackfruit (Artocarpus heterophyllus) seed-derived lectin of versatile applications in immunobiological research,
Journal of Immunological Methods 212(2) 193211 (1998). DOI: https://doi.org/10.1016/S0022-1759(98)00021-0

[13] S. Oktavia, N. Wijayanti, B. Retnoaji, Antiangiogenic effect of Artocarpus heterophyllus seed methanolic extract in ex ovo chicken chorioallantoic membrane, Asian Pacific Journal of Tropical Biomedicine 7(3) 240-244 (2017)

DOI: https://doi.org/10.1016/j.apjtb.2016.12.024

[14] S.H. Lam, H.L. Chua, Z. Gong, T.J. Lam, Y.M. Sin, Development and maturation of the immune system in Zebrafish, Danio rerio: a gene expression profiling, in situ hybridization and immunological study, Dev Comp Immunol 28 9-28 (2004). DOI: https://doi.org/10.1016/S0145-305X(03)00103$\underline{4}$

[15] S.H. Lam, H.L. Chua, Z. Gong, Z. Wen, T.J Lam, Y.M. Sin, Morphologic transformation of the thymus in developing Zebrafish, Developmental Dynamics (2002). DOI: https://doi.org/10.1002/dvdy.10127

[16] C.F. Chou, C.B. Loh, Y.K. Foo, S. Shen, B.C. Fielding, T.H.P. Tan, J. Fu, ACE2 orthologues in non-mammalian vertebrates (Danio, Gallus, Fugu, Tetraodon and Xenopus), Gene 377(1-2) 46-55 (2006). DOI: https://doi.org/10.1016/j.gene.2006.03.010

[17] S. Hoffmann, L. Mullins, C. Buckley, S. Rider, J. Mullins, Investigating the RAS can be a fishy business: Interdisciplinary opportunities using Zebrafish, Clinical Science 132(23) 2469-2481. (2018).

DOI: https://doi.org/10.1042/CS20180721

[18] J.B. Harborne, Phytochemical Methods, In Phytochemical Methods (1980). DOI: https://doi.org/10.1007/978-94-009-5921-7

[19] OECD, Test No. 236: Fish Embryo Acute Toxicity (FET) Test, OECD Publishin, 2013

[20] S.F. Sy Mohamad, S,F, Mohd, M.S. Abdul Munaim, S. Mohamad, W.M. Wan Sulaiman, Proximate composition, minerals contents, functional properties of mastura variety jackfruit (Artocarpus heterophyllus) seeds and lethal effects of its crude extract on zebrafish (danio rerio) embryos, Food Research 3(5) 546-555 (2019).

DOI: https://doi.org/10.26656/fr.2017.3(5).095

[21] C.B. Kimmel, W.W. Ballard, S.R. Kimmel, B. Ullmann, T.F. Schilling, Stages of embryonic development of the Zebrafish. Developmental 
Dynamics 203(3) 253-310 (1995). DOI: https://doi.org/10.1002/aja.1002030302

[22] A.M. Chahardehi, H. Arsad, V. Lim, Zebrafish as a successful animal model for screening toxicity of medicinal plants, Plants 9 (10) 1-35 (2020).

DOI: https://doi.org/10.3390/plants9101345

[23] S.V. Sharmili, A.J. Angelin, Stages of Embryonic Development of the Zebrafish Danio rerio (Hamilton), European Journal of Biotechnology 3(6) 06-11 (2015).

[24] S. Dworkin, S.M. Jane, Novel mechanisms that pattern and shape the midbrain-hindbrain boundary, Cellular and Molecular Life Sciences (2013). DOI: https://doi.org/10.1007/s00018012-1240-X

[25] H.C. Gibbs, A. Chang-Gonzalez, W.A. Hwang, A.T. Yeh, A.C. Lekven, Midbrain-hindbrain boundary morphogenesis: At the intersection of wnt and Fgf signaling, Frontiers in Neuroanatomy (2017). DOI: https://doi.org/10.3389/fnana.2017.00064

[26] K. Volkmann, Y.Y. Chen, M.P. Harris, M.F. Wullimann, R.W. Köster, The Zebrafish cerebellar upper rhombic lip generates tegmental hindbrain nuclei by long-distance migration in an evolutionary conserved manner, Journal of Comparative Neurology (2010). DOI: https://doi.org/10.1002/cne.22364

[27] B.P. Sampurna, G. Audira, S. Juniardi, Y.H. Lai, C.Der. Hsiao, A simple ImageJ-based method to measure cardiac rhythm in zebrafish embryos, Inventions 3(2) 1-11 (2018). DOI: https://doi.org/10.3390/inventions3020021 